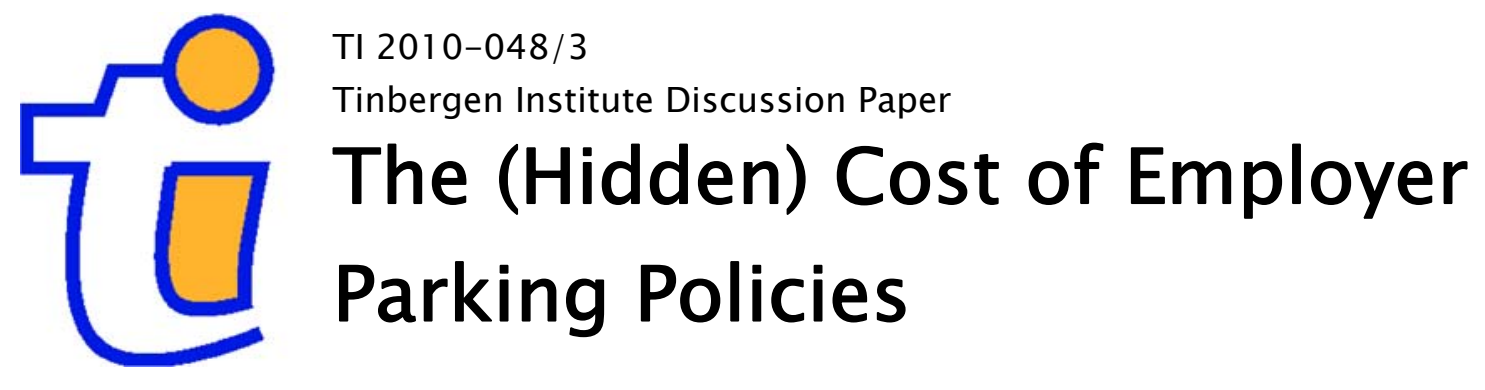

Jos van Ommeren ${ }^{1,2}$

Derk Wentink'

' VU University Amsterdam;

2 Tinbergen Institute, the Netherlands. 


\section{Tinbergen Institute}

The Tinbergen Institute is the institute for economic research of the Erasmus Universiteit Rotterdam, Universiteit van Amsterdam, and Vrije Universiteit Amsterdam.

Tinbergen Institute Amsterdam

Roetersstraat 31

1018 WB Amsterdam

The Netherlands

Tel.: +31(0)205513500

Fax: $+31(0) 205513555$

Tinbergen Institute Rotterdam

Burg. Oudlaan 50

3062 PA Rotterdam

The Netherlands

Tel.: + $31(0) 104088900$

Fax: $+31(0) 104089031$

Most TI discussion papers can be downloaded at http://www.tinbergen.nl. 


\title{
The (hidden) cost of employer parking policies
}

\author{
Jos van Ommeren \\ Derk Wentink
}

VU University, Amsterdam, The Netherlands

$4 / 29 / 2010$

Abstract. It has been argued that urban planning policies, through minimum parking requirements, and income tax policies induce free employer parking. We show that tax policies induce welfare losses in the order of $12 \%$ of parking resource costs, implying an annual deadweight loss in the order of $€ 5$ billion for Europe. In the US, due to the presence of minimum parking requirements, the deadweight loss of policy is even higher and in the order of $\$ 30$ billion.

Keywords: employer parking, tax distortion, urban planning policies.

VU University, FEWEB, De Boelelaan, 1081 HV Amsterdam, the Netherlands; Email: jommeren@feweb.vu.nl. Jos van Ommeren is affiliated to the Tinbergen Institute, Amsterdam. We would like to thank PropertyNl and in particular Kes Brattinga for providing data, Richard Arnott, Donald Shoup and Hans Koster for useful comments, Netherlands Organisation for Scientific Research (NWO) for funding and Marcel Hoogzaad for valuable assistance. 


\section{Introduction}

"There ain't no such thing as a free lunch" definitely applies to parking. Free parking (from the user's perspective) is common but has been universally argued to distort market outcomes (Arnott et al., 1991; Small, 1997). We aim to estimate the welfare costs of free parking induced by urban planning and fringe benefits taxation and show that these are huge. We focus on employer parking, where almost all parking is provided for free to the employee. ${ }^{1}$ In the US, only a few percent of the parking resource costs are paid by commuters (Small and Verhoef, 2007). However, also in countries where car use is less widespread, employer-paid parking is the norm.

There are two policy reasons why employees do not pay for employer parking. One reason, applicable to the US, is that urban planning regulations by local governments impose minimum parking requirements on buildings (an exception is downtown San Francisco). These minimum parking restrictions are excessive as the number of parking spaces far exceeds the peak occupancy even when users are not charged (see Shoup, 1997; 2005). Given excess supply of parking, employers have no incentive to charge employees (the opportunity costs are zero). Because there is little reason to impose minimum restrictions that increase parking supply, these regulations induce a deadweight loss, as society consumes too many parking spaces (Shoup, 2005). ${ }^{2}$ Despite a large literature on parking, we are not aware of empirical welfare estimates of this deadweight loss. We aim to fill this gap in the literature, which fits in a growing literature that aims to estimate the welfare effects of urban planning (e.g. Glaeser et al., 2005; Cheshire and Hilber, 2008).

\footnotetext{
${ }^{1}$ For employees, employer-provided parking is much more important than curb parking. For example, in the Netherlands, about $80 \%$ of car commuters use employer-provided parking.

${ }^{2}$ One exception is when on-street parking is not priced, so commuters cruise for parking spaces, which causes external costs (Arnott and Inci, 2006). By imposing that employers provide free parking, the external costs of cruising will be reduced. Since on-street pricing is straightforward to implant, it would be hard to argue that minimum parking restrictions can be justified.
} 
The second reason is that employer parking is not taxed as a fringe benefit in kind, inducing employers to offer parking spaces to employees for free while simultaneously reducing wages (Katz and Mankiw, 1985). This is particularly relevant for European countries, where income and value added taxes are higher than in the US, so the implicit subsidy is larger. For example, in the Netherlands, the marginal labour income tax rate is 0.42 for most car commuters, and VAT is 0.20 , so, for most commuters the implicit subsidy is 54 percent $(0.42+0.20 \times 0.58)$ of the resource costs. ${ }^{3}$

A common conclusion in the economics literature is that the deadweight loss created by inappropriate taxing of fringe benefits is negligible (Turner, 1987), but employer-paid parking has been completely ignored. Employer-paid parking is a common and costly fringe benefit (the average annual cost is about $€ 750$ per parking space) but is not taxed as a benefit in kind. ${ }^{4}$ Hence, another gap in the literature that we aim to fill is to estimate the deadweight loss of a shift in parking demand caused by not taxing employer-parking benefits. This study is therefore complementary to the large literature on car taxation and in particular gasoline taxation, which receives much attention in the literature (e.g. Bento et al., 2009).

We focus on the Netherlands where minimum parking restrictions are absent. Some Dutch municipalities use maximum parking restrictions for new buildings at certain locations, but these restrictions are usually non-binding. Restrictions typically imply that the ratio of parking places to employees must be less than 0.83 , which far exceeds the average proportion of employees that drive by car (0.55)(CROW, 2008), although in some locations (e.g. near railway stations in large cities) the maximum restrictions are lower and binding. By comparison, in the US, the standard 'golden rule' of office planning is that there must by at least 4 parking spaces per 1,000 square feet (Shoup, 2005, p. 608), implying that the ratio of

\footnotetext{
${ }^{3}$ We ignore employer taxes on labour that are used for pensions and unemployment benefits, because these taxes generate future benefits.

${ }^{4}$ In urban areas the costs are much higher. For example, in Amsterdam, the average cost is $€ 1,600$, whereas in the centre of Amsterdam it is about 3,000 Euro
} 
parking places, to employees, exceeds 1.3. Because land (and parking) prices are determined in competitive markets, it is reasonable to assume that employers consume parking on their parking demand function.

According to classical welfare economics, the welfare implications of policies that distort employer-provided parking markets depend on the firms' parking demand and supply functions. Firm demand functions reflect employee demand functions. In a competitive labour market without distortions, the firm and employee demand function are identical. In the current paper, we estimate these functions for Dutch employers, using information about the employers' cost of providing parking to employees. This information is rather unique as there is currently a lack of information of these costs (see Small and Verhoef, 2007, p. 113). We use information from nation-wide office property transactions (collected by real estate agents) where information about the number of parking spaces and parking prices is separately reported. In the rest of the paper, we proceed as follows. In section 2, we introduce the employer parking data. In section 3, we estimate the firms' parking demand and supply functions and provide deadweight losses of distortionary policies. Section 4 concludes.

\section{Office parking data}

Data about parking have been obtained from a publisher (PropertyNl) which receives nationwide commercial property transactions from real estate agents. These data refer to properties with a minimum size of $200 \mathrm{~m}^{2}$, so small properties are excluded. The publisher sets a number of requirements to the information provided by real estate agents. ${ }^{5}$ Agents are obliged to provide information about location, type of building (e.g. office space) and property size, but are not obliged to provide information about prices or certain specific characteristics of the building, including parking.

\footnotetext{
${ }^{5}$ The property is advertised (on internet) and the transaction is published (in the publisher's magazine).
} 
We use observations for the years 2001-2007 that refer to rented office buildings (about half of property transactions belong to this group). We select office buildings, because for these buildings about 95\% of parking demand is generated by employees (CROW, 2008). Hence, for office buildings, the firms' demand for parking is synonymous with the firms' demand for parking space used by employees. The data do not allow us to distinguish between offices without any parking and offices where information about the number of parking spaces is missing. Hence, we are constrained to work with a sample of observations with at least one parking space. This does not create a selection bias, because the data refer to large properties that almost always have some parking.

For many offices, only a part of the advertised property is transacted (so for example, 3,000 square meter and 30 parking spaces are advertised and only 1,000 square meter and then parking spaces are transacted). We have estimated separate models using advertised and transacted characteristics which are presented in an appendix. As the results are similar (but less reliable because the instruments are less strong), and average parking price for transactions is only $0.5 \%$ lower than for advertised properties, we pool data on transacted properties with advertised properties (when the transacted properties are missing).

The resulting rather unique office dataset includes 8,935 observations. For 2,931 observations we know the annual rent per parking lot, which we label the parking price. The results we present in the current paper are based on these observations. We have investigated whether this creates a selection bias with a two-step Heckman correction model. In the first step we use as instrument a dummy variable which captures whether or not there is information about the building's annual rent. The idea behind this instrument is that providing information about the building's rent should be positively correlated with the probability of providing information about parking but this should not be correlated to the demand or supply of parking. The results with a Heckman correction (that explicit models the potential selection 
bias) are identical to the ones without a Heckman correction. So we will only report the latter ones. Apparently, the reporting of the parking price is not related to the demand for parking.

\section{Empirical results}

Table 1 provides the descriptives of the variables in our analysis. The average price for a parking spot is $€ 758$ per year, with a standard deviation of $€ 509$ (for $95 \%$ of all observations, the price is between $€ 250$ and $€ 2,400$ ). ${ }^{6}$ The average office size (excluding parking) is 1,378 square metres $\left(14,978\right.$ square feet). ${ }^{7}$ The average number of parking spots is 26 . On average, firms' expenditure on parking is $8.8 \%$ of office building expenditure.

We aim to estimate the demand for parking as a function of parking price controlling for office size, distance to the closest highway ramp and distance to the nearest train station. The dependent and explanatory variables are in logarithms. In addition, control dummies are added for the year of transaction.

To identify the demand for parking, we use a 2SLS approach, using several specifications. In the first specification, we do not use any other controls than the aforementioned explanatory variables. In two other specifications, we control for 129 municipalities, or 516 area fixed effects respectively. Controlling for municipalities is useful, because it controls for differences in municipality regulations regarding parking. Controlling for municipalities may not be sufficient, however, to control for unobserved spatial variation in demand or supply factors as well as for within municipality variation in policy. We, therefore, also use areas fixed effects defined by four digit postcodes. The areas are quite small: the average distance between properties belonging to the same postcode area is only 612 metres, which makes it plausible that unobserved spatial heterogeneity is minimal.

\footnotetext{
${ }^{6}$ This average price is not the average price faced by employees. To calculate the latter, we have calculated the average weighted price, using the number of parking spaces per firm as weights. The average weighted price is $€$ 754 , so only $€ 4$ lower.

${ }^{7}$ One employer uses on average $30-35 \mathrm{~m}^{2}$, so the average workforce of these firms is about 40 to 50 employees.
} 
We instrument parking price with the construction year of the office (which is provided for $64 \%$ of the observations, see Table 1). Construction year is a valid instrument as it affects the current price of parking through historical supply decisions without directly affecting demand, ${ }^{8}$ because it reflects land prices (and the conventional parking norm) at the time of construction and therefore historical building costs. ${ }^{9}$ F-tests, provided at the bottom of Table 2 , indicate that the effect of construction year on parking price is sufficiently strong to be used as an instrument in the demand function.

Table 1: Descriptives

\begin{tabular}{lcc}
\hline & Mean & Std. deviation \\
Parking price $(€)$ & 758,25 & 509.70 \\
Parking spaces & 25.80 & 41.20 \\
Office size (square metres) & 1,378 & 2,240 \\
Parking expenditure/building expenditure & 0.088 & 0.057 \\
Distance to nearest highway ramp (metres) & 1,858 & 1,577 \\
Distance to nearest train station (metres) & 1,693 & 1,568 \\
Construction year & & \\
Missing & 0.36 & 0.48 \\
Before 1970 & 0.04 & 0.19 \\
1970-1980 & 0.05 & 0.21 \\
1980-1990 & 0.15 & 0.36 \\
1990-2000 & 0.20 & 0.40 \\
After 2000 & 0.20 & 0.40 \\
\hline
\end{tabular}

The results are presented in Table 2. Our main result is that the price demand elasticity ranges between -0.918 and -0.612 . The results in column 3 of Table 2, where we control for area effects, and which are likely most reliable, indicate a price demand elasticity of -0.612 with a standard error of $0.150 .{ }^{10}$ Further, note that office size, which captures number of employees, has a unit demand elasticity.

\footnotetext{
${ }^{8}$ See Appendix Table A2 for the results of the first steps of the 2SLS regressions. We only provide the first step where we use area controls. The other first steps are similar and can be received upon request.

${ }^{9}$ As emphasised by Arnott and Rowse (2009), it is usually prohibitively expensive to increase parking (e.g. under the ground) after construction. For example, buildings constructed between 1980 and 1990 (when land was relatively cheap) have nowadays still more parking spaces.

${ }^{10}$ Appendix Table A1 provides the results of separate analyses using advertised and transacted information. Using transactions, the demand elasticity is close to unity, whereas using advertising the point estimate is -0.435 . The results of OLS regressions, not reported here, suggest a negative, but lower price demand elasticity (in absolute value).
} 


\begin{tabular}{lccc}
\hline & 2SLS & 2SLS FE & 2SLS FE \\
\hline $\log ($ price) & $(1)$ & $(2)$ & $(3)$ \\
& -0.834 & -0.918 & -0.612 \\
$\log$ (office size) & $(0.146)$ & $(0.186)$ & $(0.150)$ \\
& 0.985 & 0.980 & 0.970 \\
$\log$ (distance to highway) & $(0.015)$ & $(0.014)$ & $(0.012)$ \\
& -0.049 & -0.003 & -0.058 \\
$\log$ (distance to train station) & $(0.015)$ & $(0.031)$ & $(0.032)$ \\
& -0.034 & -0.044 & 0.020 \\
year dummies & $(0.029)$ & $(0.032)$ & $(0.033)$ \\
area fixed effects & yes & yes & yes \\
municipality fixed effects & no & no & yes \\
\hline no. of fixed effects & no & yes & yes \\
average group size & & 128 & 516 \\
\hline F-test for weak instruments (construction year) & 12.46 & 12.81 & 24.33 \\
Robust standard errors are in parentheses. & & &
\end{tabular}

We have re-estimated this model to examine how sensitive the results are to specification. We included area fixed effects defined by six digit postcodes. The main advantage is that the average distance between properties belonging to the same six digit postcodes area is only 71 metres (and less than $200 \mathrm{~m}$ for 90 percent of the observations), so unobserved heterogeneity with respect to the economic environment can be completely assumed away. The main disadvantage of adding so many fixed effects is that for 734 observations there is not another observation in the same postcode area and for the other 2,197 observations, 814 fixed effects are included, so the degrees of freedom are strongly reduced. Nevertheless, it appears just possible to estimate the price demand elasticity with some precision: it is -0.416 with a s.e. of 0.230 , so it is still statistically significant at the $10 \%$ level. This point estimate is not too far from the -0.612 point estimate using four digit postcode dummies. This gives confidence that our estimates are not driven by unobserved heterogeneity in local factors. Furthermore, models based on more selective samples were estimated (e.g. a sample without Amsterdam where parking prices are about twice the national average), but the results remain robust. 
The second part of the empirical analysis entails identifying the firm's parking supply function. Let us suppose that the supply function is horizontal, so there are no economies of scale in constructing parking spaces at the level of the firm. Given this assumption, any valid instrument (hence, any variable which shifts the demand function, but which does not shift the supply function) will be statistically weak, because a horizontal supply curve implies, by definition, that the equilibrium price is constant. In other words, the effect of the instrument on the price (in the first step) is absent (despite a large shift in the demand function). Office size has an extremely strong effect on parking demand (the office size elasticity of demand is unity, with a t-value of 60). However, when we use this variable as an instrument in the first step of the instrumental variable analysis, we do not find any effect on parking price, implying that the firm's parking supply curve is (almost) horizontal (see last column of Table A2 in the Appendix: the coefficient of $\log ($ size) is 0.010 with a standard error of 0.007$)$. This makes sense, at least for larger properties analysed here.

\section{Welfare implications}

The price elasticities allow us to examine the welfare effects of policy distortions. We assume that the estimated elasticities are invariable with the distortive policy examined and that issues regarding congestion and pricing of on-street parking are of second order. We also assume that the labour market is competitive. Given a horizontal supply function and a log-linear demand function with price elasticity $\beta$, the deadweight loss per firm equals $q_{1}\left(p_{1}-p_{0}\right)-(1+\beta)^{-1}\left(p_{1} q_{1}-p_{0} q_{0}\right)$ for $\beta \neq-1$, where $p$ and $q$ represent the parking price and number of parking places respectively. The subscript 0 denotes the market outcome given a non-distortionary policy, whereas the subscript 1 denotes the outcome given a distortionary policy. Our welfare analysis will be based on the average parking price in our data, and relies

on the assumption that the price paid by firms reflects the resource costs of parking. Because 
some (but not all) municipalities use maximum restrictions for certain locations, it may be the case that due to restrictive supply the average price is somewhat above the average resource costs. However, given strong competition of office buildings between different municipalities (office vacancy rates are 5 to $15 \%$ in most areas), this is likely a minor issue.

\subsection{Distortionary taxation of parking fringe benefits}

Employees who obtain a parking place from their employer do not pay any income tax (or VAT) on this fringe benefit, which shifts the firms' parking demand curve to the right (as employers will substitute parking for wages). The deadweight loss is calculated using market averages. In line with information provided in the introduction, we assume now that the effective parking price faced by employers is exactly $50 \%$ of the resource cost. Average employer parking cost is about $€ 750$ (see Table 1 ), so $\mathrm{p}_{0}=750$ and $\mathrm{p}_{1}=375$. Further, according to this table, the average number of parking spaces $\mathrm{q}_{1}$ equals 26 . Using a demand elasticity of -0.612 , this implies that $\mathrm{q}_{0}=17$. Hence, the policy not to tax parking as a fringe benefit increases the number of parking spaces by about one third. ${ }^{11}$ The annual deadweight loss is then $€ 2,250$, about $€ 90$ per parking spot. So, on average about $12 \%$ of Dutch employer parking expenses are a deadweight loss. In the Netherlands, there are about 3 million employer-provided parking spaces (Van Dijken, 2002), so the annual welfare loss is about $€ 270$ million. For Europe as a whole, assuming that the welfare loss per parking space (and the ratio of employer parking spaces and employees) is the same as in the Netherlands, the implied annual welfare loss is in the order of $€ 5$ billion. Any other welfare losses of these policies due to increased energy use, pollution, congestion and reduced agglomeration are excluded here (Parry and Small, 2005), although these additional losses may be small in the Netherlands where present fuel taxes already partially capture these externalities.

\footnotetext{
${ }^{11}$ Such an estimate seems reasonable as it must be interpreted as a long-run estimate. The short-run demand for parking is quite elastic when user-charges are introduced for employees (Shoup, 2005), but the long-run estimate which allows for employee sorting based on workplace and residence is likely much higher.
} 


\subsection{Minimum parking restrictions}

We consider now a hypothetical policy that imposes minimum restrictions, such as prevalent in the US, which effectively reduces the price of parking to zero. This policy creates an excess supply to levels where the parking demand function is likely discontinuous. For example, the firm's inverse parking demand function drops to zero when the number of parking spaces exceeds the number of employees. To avoid discontinuities, we consider a policy that increases supply by 30\% above current (already distorted by benefits taxation) levels. Shoup (2005) provides evidence that minimum restrictions at US offices are usually 30\% above peak demand when users are not charged. Given a demand elasticity of -0.612 , an exogenous increase of $30 \%$ in supply (from 26 to 34) due to minimum restrictions reduces the parking price from $€ 375$ to $€ 241$, so by 32 percent. Given $\mathrm{p}_{0}=750, \mathrm{q}_{0}=17, \mathrm{p}_{1}=241$ and $\mathrm{q}_{1}=34$, the annual deadweight loss per firm is $€ 5,916$, about $€ 227$ per parking spot, so about $30 \%$ of the parking expenses are a deadweight loss. ${ }^{12}$ US employer parking expenses are estimated to be about $\$ 100$ billion per year, so the implied deadweight loss is estimated to be in the order of $\$ 30$ billion per year. This excludes the additional welfare losses because of increased externalities which have been argued to be substantial in the US. Our point estimates will not exactly hold for the US, because the spatial structure of the US is not comparable to the Netherlands (which resembles Los Angeles in size and spatial structure). Nevertheless, the implication that current US urban planning policies are extremely distorting is likely to hold.

\section{Conclusion}

In a series of papers, Shoup has argued that US urban planning through minimum parking requirements, as well as distortionary tax policies regarding free parking benefits, lead to

\footnotetext{
12 Hence, in the Netherlands, conditional on current tax practices, the introduction of minimum parking restrictions would induce an annual deadweight loss of around $€ 137$ per parking space (€ 227- € 90) about $18 \%$ of parking expenses.
} 
large welfare losses (e.g. Shoup, 1997; Shoup, 2005). Our empirical research supports this conclusion. Minimum parking requirements and tax policies in the US are estimated to induce a deadweight loss of about $30 \%$ of resource parking cost, so about 30 billion per year. This excludes other welfare losses of these policies due to increased energy use, pollution, congestion and reduced agglomeration. For Europe, the welfare loss is estimated to be about $12 \%$ of the resource parking costs, approximately $€ 5$ billion per year. 


\section{Literature}

Arnott, R., A. De Palma and R. Lindsey (1991), A temporal and spatial equilibrium analysis of commuter parking, Journal of Public Economics, 45, 301-335

Arnott, R. and E. Inci (2006), An integrated model of downtown parking and traffic congestion, Journal of Urban Economics, 60, 418-442

Arnott, R. and J. Rowse (2009), Downtown parking in auto city, Regional Science and Urban Economics, 39, 1-14

Bento, A., L. Goulder, M. Jacobsen and R.H. von Haefen (2009), Distributional and efficiency impacts of increased US gasoline taxes, American Economic Review, 99, 3, 667-699

Cheshire, P.C. and C.A.L. Hilber (2008), Office space supply restrictions in Britain: the political economy of market revenge, Economic Journal, 118, F185-F221

CROW (2008), Parkeercijfers - basis voor parkeernormering, EDE, Netherlands

Glaeser, E.L., J. Gyourko and R.E. Saks (2005), Why is Manhattan so expensive? Regulation and the size in house prices, Journal of Law and Economics, 48, 2, 331-369

Katz, A. and Mankiw, G. (1985), How should fringe benefits be taxed, National Tax Journal, $38,1,37-47$

Parry, I.W.H. and K.A. Small (2005), Does Britain or the United States have the right gasoline tax? American Economic Review, 95, 4, 1276-1289

Shoup, D.C. (1997), Evaluating the effects of cashing out employer-paid parking: eight case studies, Transport Policy, 4(4), 201-216

Shoup, D.C. (2005), The High Cost of Free Parking, Planners Press, Chicago

Small, K.A. (1997), Economics and urban transport policy in the United States, Regional Science and Urban Economics, 27, 671-691

Small, K.A. and E.T. Verhoef (2007), The Economics of Urban Transportation, Routledge 
Turner, R.W. (1987), Taxes and the number of fringe benefits received, Journal of Public Economics, 33, 41-57

Van Dijken (2002), Parkeren in Nederland, IOO 
$\underline{\text { Appendix }}$

Table A1. Demand for parking (in log)

\begin{tabular}{lcccccc}
\hline & \multicolumn{3}{c}{ Transactions } & \multicolumn{3}{c}{ Advertised } \\
\hline & 2SLS & 2SLSFE & 2SLSFE & 2SLS & 2SLSFE & 2SLSFE \\
\hline $\log ($ price) & $(1)$ & $(2)$ & $(3)$ & $(4)$ & $(5)$ & $(6)$ \\
& -0.676 & -1.372 & -0.969 & -0.875 & -1.036 & -0.435 \\
$\log$ (office size) & $(0.197)$ & $(0.277)$ & $(0.187)$ & $(0.151)$ & $(0.221)$ & $(0.146)$ \\
& 0.996 & 0.997 & 1.001 & 0.998 & 0.984 & 0.946 \\
$\log$ (distance to highway) & $(0.016$ & $(0.020)$ & $(0.016)$ & $(0.020)$ & $(0.018)$ & $(0.013)$ \\
& -0.044 & 0.076 & 0.074 & -0.009 & 0.039 & 0.015 \\
$\log$ (distance to train station) & $(0.020)$ & $(0.044)$ & $(0.034)$ & $(0.018)$ & $(0.034)$ & $(0.025)$ \\
& 0.010 & -0.104 & -0.108 & -0.040 & -0.074 & -0.028 \\
year dummies & $(0.035)$ & $(0.045)$ & $(0.037)$ & $(0.026)$ & $(0.036)$ & $(0.024)$ \\
area fixed effects & yes & yes & yes & yes & yes & yes \\
municipality fixed effects & no & no & yes & no & no & yes \\
\hline number of observations & no & yes & yes & no & yes & yes \\
number of fixed effects & 1,719 & 1,719 & 1,719 & 2,423 & 2,423 & 2,423 \\
average group size & & 100 & 414 & & 121 & 469 \\
\hline F-test for weak instruments (construction year) & 4.99 & 6.18 & 11.49 & 12.20 & 9.24 & 24.66
\end{tabular}


Table A2. First steps in 2SLS: dependent variable: log(price)

\begin{tabular}{|c|c|c|c|}
\hline & Transacted & Advertised & Pooled \\
\hline & (1) & (2) & (3) \\
\hline \multirow[t]{2}{*}{$\log$ (office size) } & -0.000 & 0.024 & 0.010 \\
\hline & $(0.011)$ & $(0.007)$ & $(0.007)$ \\
\hline \multirow[t]{2}{*}{$\log$ (distance to highway) } & 0.067 & 0.072 & 0.072 \\
\hline & $(0.022)$ & $(0.014)$ & $(0.013)$ \\
\hline \multirow[t]{2}{*}{$\log$ (distance to train station) } & -0.137 & -0.087 & -0.096 \\
\hline & (0.019) & $(0.013)$ & 0.012 \\
\hline \multicolumn{4}{|c|}{ Instruments (construction year) } \\
\hline \multirow[t]{2}{*}{ built $1970-1980$} & -0.004 & -0.061 & -0.023 \\
\hline & $(0.068)$ & $(0.049)$ & $(0.045)$ \\
\hline \multirow[t]{2}{*}{ built $1980-1990$} & -0.141 & -0.120 & -0.144 \\
\hline & $(0.062)$ & $(0.042)$ & $(0.040)$ \\
\hline \multirow[t]{2}{*}{ built $1990-2000$} & -0.049 & -0.029 & -0.044 \\
\hline & $(0.061)$ & $(0.042)$ & (0.039) \\
\hline \multirow[t]{2}{*}{ built $2000-2007$} & 0.141 & 0.175 & 0.143 \\
\hline & $(0.062)$ & $(0.043)$ & $(0.040)$ \\
\hline \multirow[t]{2}{*}{ building year missing } & 0.015 & 0.036 & 0.006 \\
\hline & $(0.058)$ & $(0.040)$ & $(0.037)$ \\
\hline year dummies & yes & yes & yes \\
\hline area fixed effects & yes & yes & yes \\
\hline municipality fixed effects & yes & yes & yes \\
\hline number of observations & 1,719 & 2,423 & 2,961 \\
\hline number of fixed effects & 414 & 469 & 516 \\
\hline average group size & 4.2 & 5.2 & 5.7 \\
\hline
\end{tabular}

Robust standard errors are in parentheses. 